\title{
Tattoo Machines, Needles and Utilities
}

\author{
Frank Rosenkilde
}

Bel Air Tattoo, Copenhagen, Denmark

\begin{abstract}
Starting out as a professional tattooist back in 1977 in Copenhagen, Denmark, Frank Rosenkilde has personally experienced the remarkable development of tattoo machines, needles and utilities: all the way from home-made equipment to industrial products of substantially improved quality. Machines can be constructed like the traditional dual-coil and single-coil machines or can be e-coil, rotary and hybrid machines, with the more convenient and precise rotary machines being the recent trend. This development has resulted in disposable needles and utilities. Newer machines are more easily kept clean and protected with foil to prevent crosscontaminations and infections. The machines and the tattooists' knowledge and awareness about prevention of infection have developed hand-in-hand. For decades, Frank Rosenkilde has been collecting tattoo machines. Part of his collection is presented here, supplemented by his personal notes.
\end{abstract}

() 2015 S. Karger AG, Basel

\section{Electrical Tattooing}

Before tattoo machines came into use, various types of handheld needles and other tools were used for tattooing, and I can only imagine that it must have been a good sales technique to be able to advertise electrical tattooing around 1890, when the electrical tattooing machines were developed. In this period, several persons applied for patents. The American Sam O'Reilly based his patent on Thomas Edison's electrical pen principle, which is a type of rotary machine. Londonbased Thomas Riley applied for a patent on a single-coil machine, and Alfred Charles South, who was also a Londoner, applied for a patent on a twin-coil machine. Technically, the modern machines are based on these principles, but they have, of course, been refined. Part of the author's collection of tattoo machines and equipment is presented in figs. 1-17, supplemented with detailed information in the legends.

Numerous types of machines that could be used for line, colour or shading functions have been developed over the years; some electrical, some even air powered, including dual-coil machines, single-coil machines, e-coil machines, rotary machines, hybrid machines. We could devote a whole book to the technical variations of all of these machines. Until recently, the dual-coil machine has been the most common in the world, but the refined technique behind the new rotary machines allows for adjustments that have been lacking in the old types.

The dual-coil machine is based on the same principle as the electrical doorbell. Its two coils cre- 
Fig. 1. This photo shows two types of tattoo machines. Old coil machines with fixed tubes and needles are shown in the upper row. This type is still used widely today. The bottom row shows different types of rotary machines with disposable grips. The main difference lies in the weight, materials and possibility of changing tubes and needles, a need that former times did not recognise.

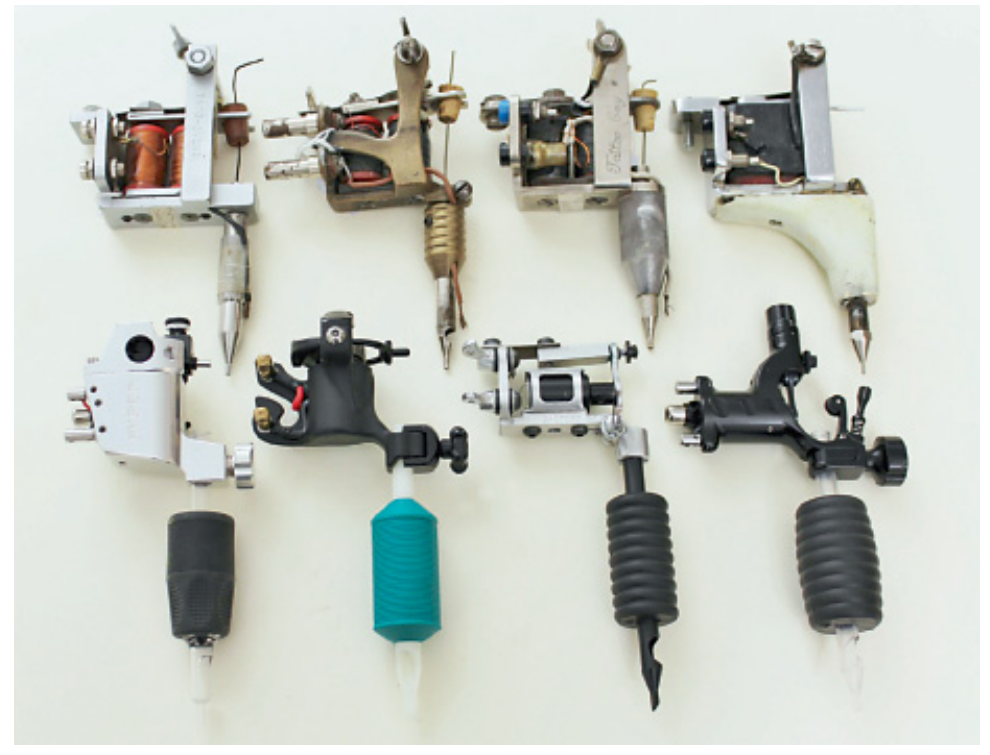

Fig. 2. The machine on the left is an old coil machine from around 1980, one of the first homemade machines I ever used. It has a nondisposable grip. A small, very light rotary machine from 2012 is shown next to it for comparison. It has a disposable plastic grip. Compared to the almost soundless and vibration-free rotary machine, the old machine is very noisy and vibrates violently. This is something that can be felt in the fingers after many years of working as a tattoo artist. The old machines weighed up to $400 \mathrm{~g}$; the rotary machine on the right weighs $80 \mathrm{~g}$.

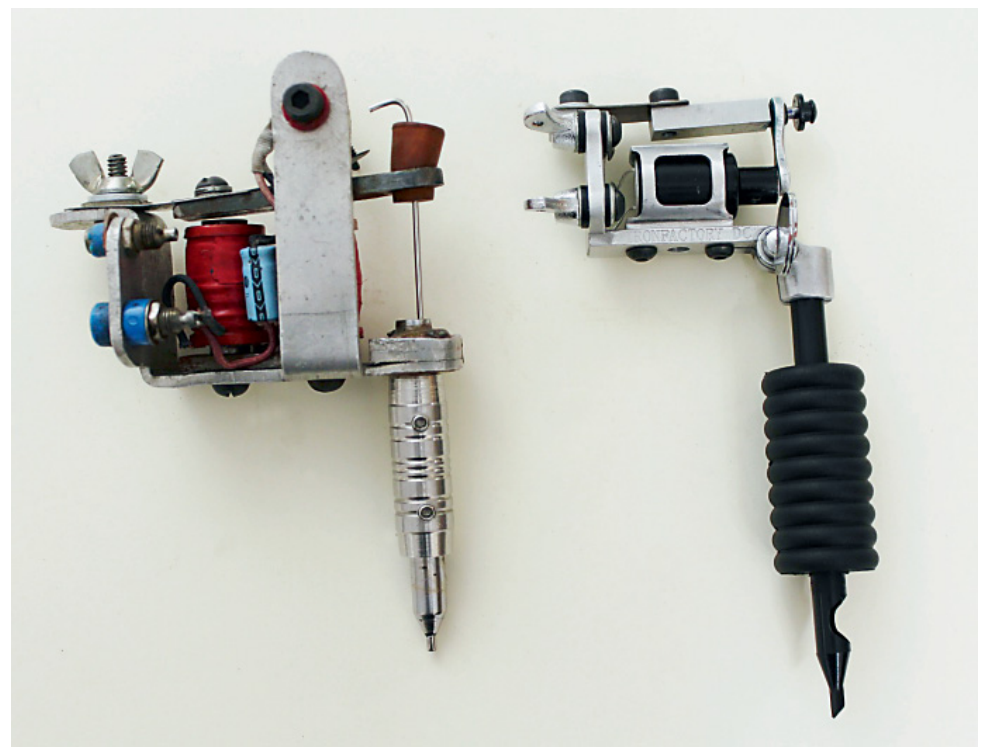

ate an electromagnetic circuit, which makes the needle move up and down. The size of the coil and the number of copper wire wraps determine the strength of the machine. A liner can have eightwrap coils, and a colour/shader may have 10-12 wrap coils.
A dual-coil machine consists of several components: the frame, which can be made of, for instance, brass, iron or aluminium, two copperwire coils, a front and a back switch screw, a top adjustment screw, front and back springs, screws and washers, and a locking mechanism for the 
Fig. 3. This is a picture of a workstation covered in plastic. The special rotary machine, with its disposable needles, is ready to be assembled. The partially unpacked needle is of a type in which the tip is clicked into the tube. This system has become increasingly popular as price and availability have improved.

Fig. 4. Workstation with a special rotary machine for click-system needles. Two machines are covered in plastic, as are the wire, the bottle and the power supply; the two machines in front are uncovered.
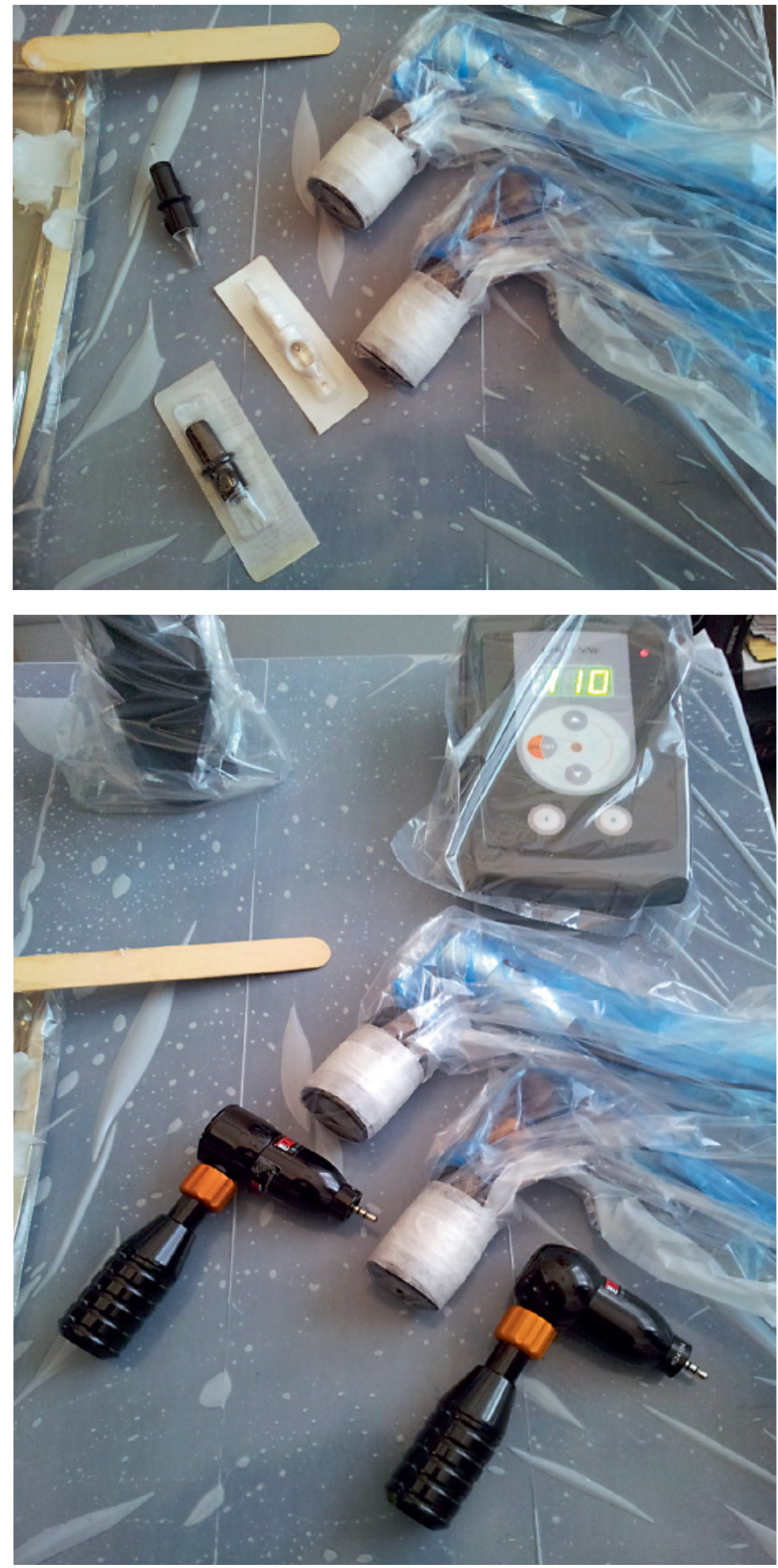
Fig. 5. Disposable needles and tubes. They come in sterile packaging and are mostly manufactured in China. They are usually of good quality, but in order to be $100 \%$ certain of quality and sterilisation, it is important to buy from a trustworthy supplier.
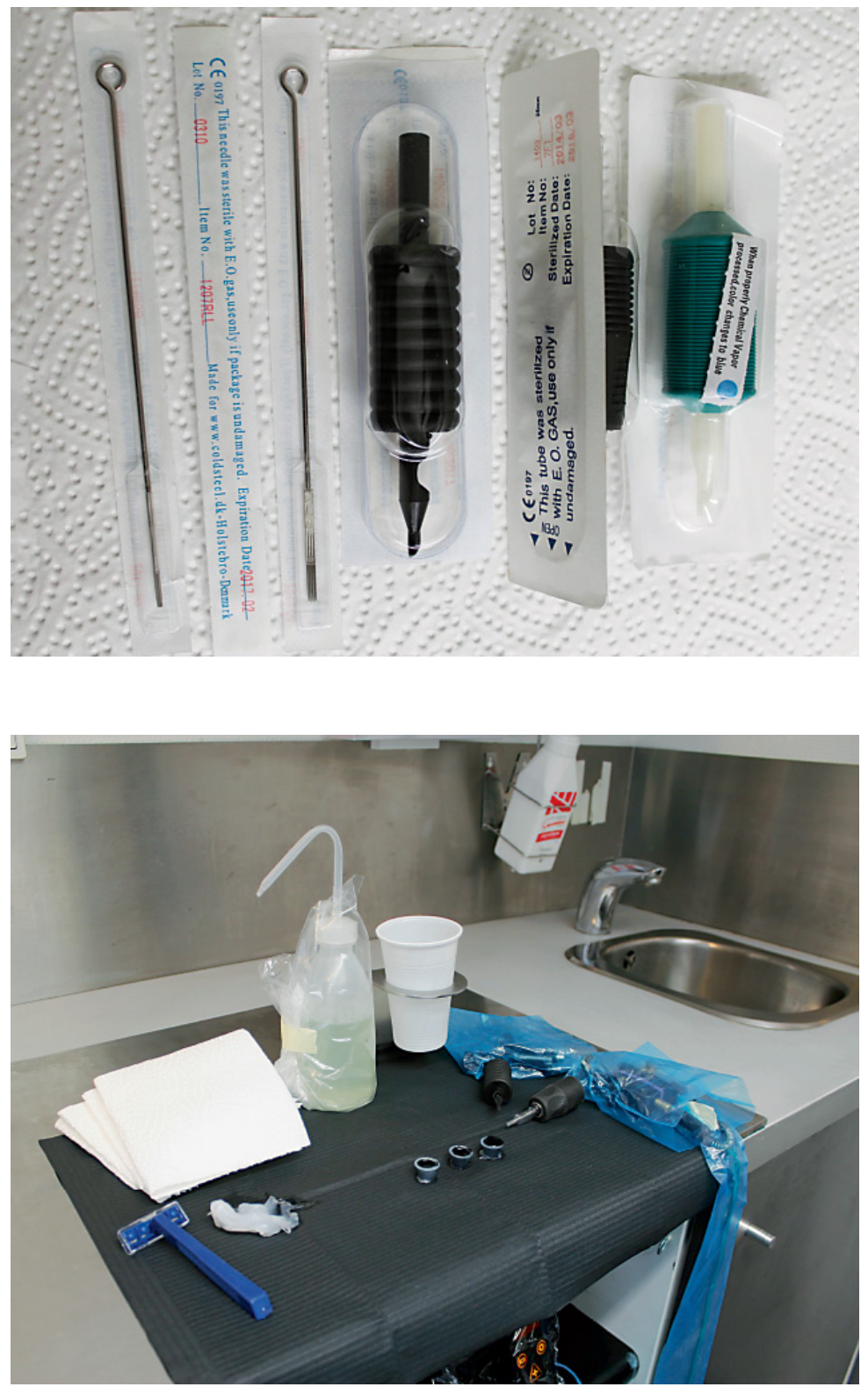

Fig. 6. A workstation on which all contact surfaces have been covered. Machines, wire, bottle (covered by a bag), machines with disposable grips and needles, disposable razor, jar, ink cups, ink and other objects. grip, which forms an integrated part of the machine.

The combination of springs, hard/soft and short/long, and the distance to the top switch, with its adjustment screw, determine the impact of the needle. A liner machine, for instance, may have short, hard springs and a short distance to the top switch, which makes it run fast and consistently compared to a colour/shader machine, with its long, soft springs, which may run fast, but has a softer impact.

An adjustable power supply is used to set the speed; a liner machine with 8-wrap coils needed for a thin, three-needle line may run at 5-7 volts, 
Fig. 7. A workstation after completion of a job. All material used for covering as well as the ink, excess Vaseline, razor, jar and needles will be disposed of. In the back, the container for used needles and various cleaning agents are shown.
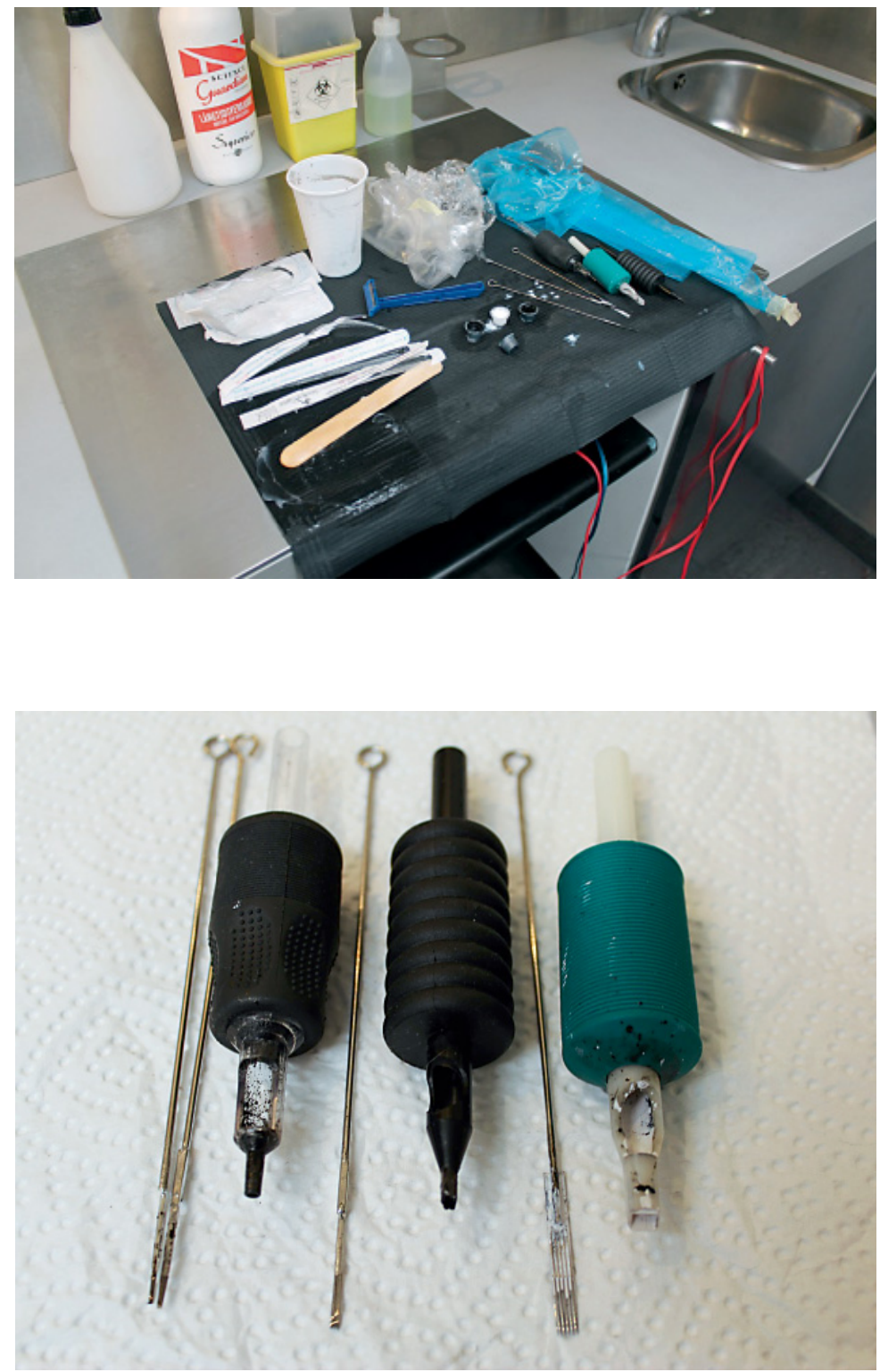

Fig. 8. Used disposable tubes and needles. whereas a colour/shader machine with up to 15 needles may run at $7-10$ volts.

Rotary machines have undergone a remarkable development over the last 10 years, but they are still powered by a small electrical engine. However, the old-fashioned direct drive with a shaft that forces the needle to go up and down usually has no adjustment possibilities, except for speed control, and an inexperienced tattoo artist may damage the customer's skin if he is unfamiliar with the machine.

There are many types of rotary machines being manufactured today: direct drive, hybrid, swash-drive, etc. Some are fitted with adjustment 


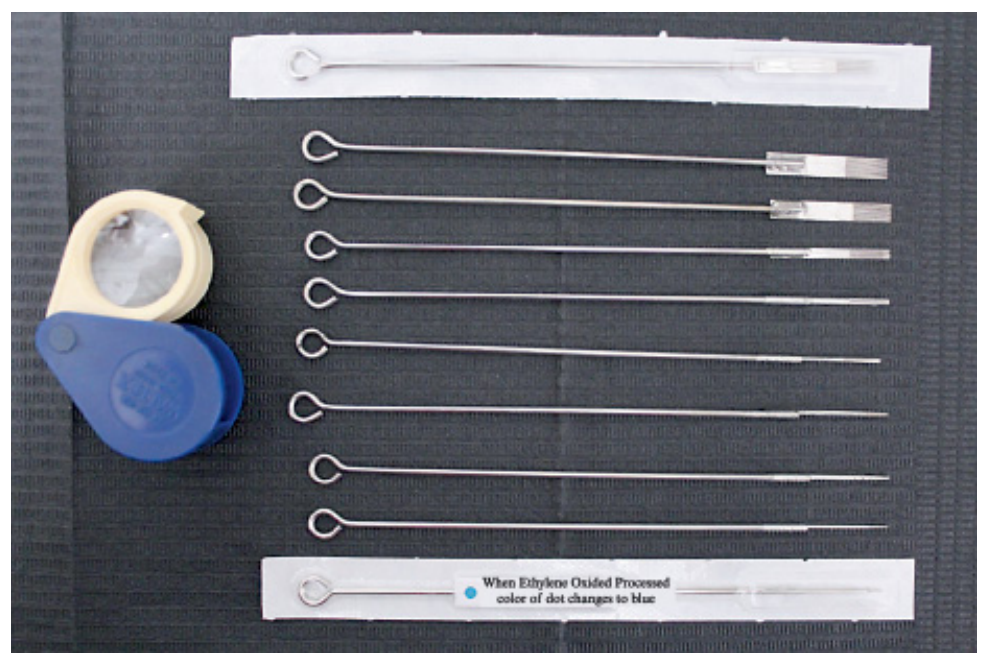

Fig. 9. Disposable needles are shown inside and outside their packaging. In the lower part of the figure, line needles and colour needles are shown; in the upper part of the figure, magnums, colour and shading needles. The thickness, length and point of a needle are all essential for the type of tattoo that is wanted. What we call a needle actually consists of several needles that are soldered together in various ways. A 'round' needle that is tightly soldered into a pointed shape may hold up to fifteen needles. This is used for outlining a tattoo. A soldering of up to fifteen needles will be used for colouring and shading. Magnums/flatshaders are soldered in layers. The larger the tattoo (for instance, a back tattoo with background), the larger the number of needles.

Fig. 10. With the use of a magnifying glass, it is possible to see if a needle is faulty or damaged. If you hit a sharp edge with the needle while working on a tattoo, the point may get flattened. The quality of needles from good suppliers is generally high, but if a customer bleeds excessively, it is important to check the needle to make sure that it is not causing the bleeding. A star pattern at the tip end of the needle means that it is faulty and must be disposed of.

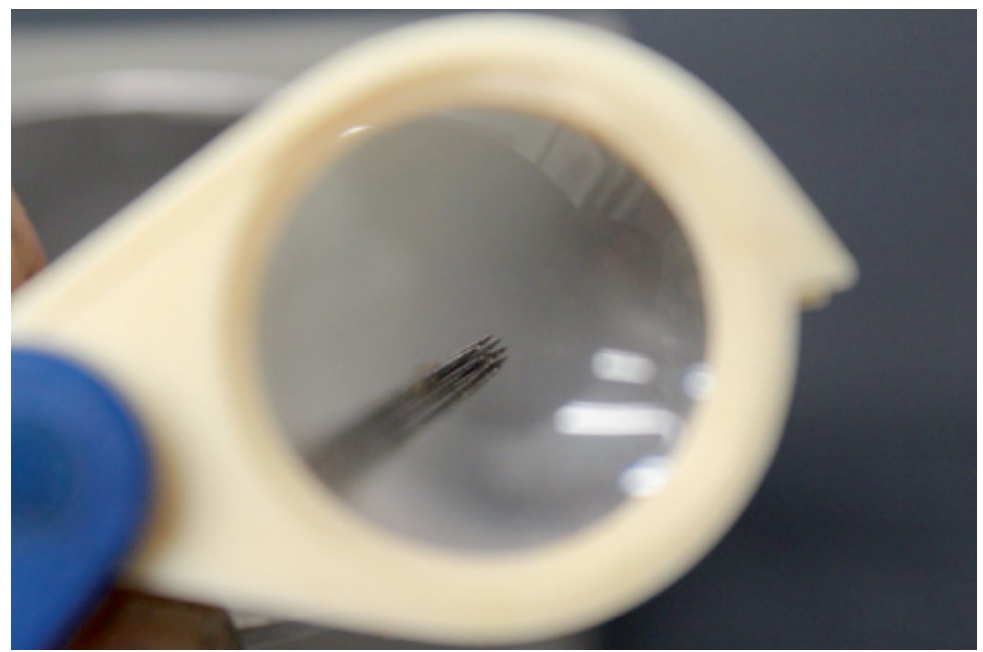


Fig. 11. Before the tattoo business developed into the industry that it is today, all tattoo artists made their own needles. This photo shows a selection of such needles. It took many hours to solder the needles into various combinations using jigs, soldering water, tin, metal sticks, etc. People had their own little tricks and, for lack of a better alternative, used ordinary sewing needles. But, over the years, we were able to get hold of better needles that mostly were manufactured in England.
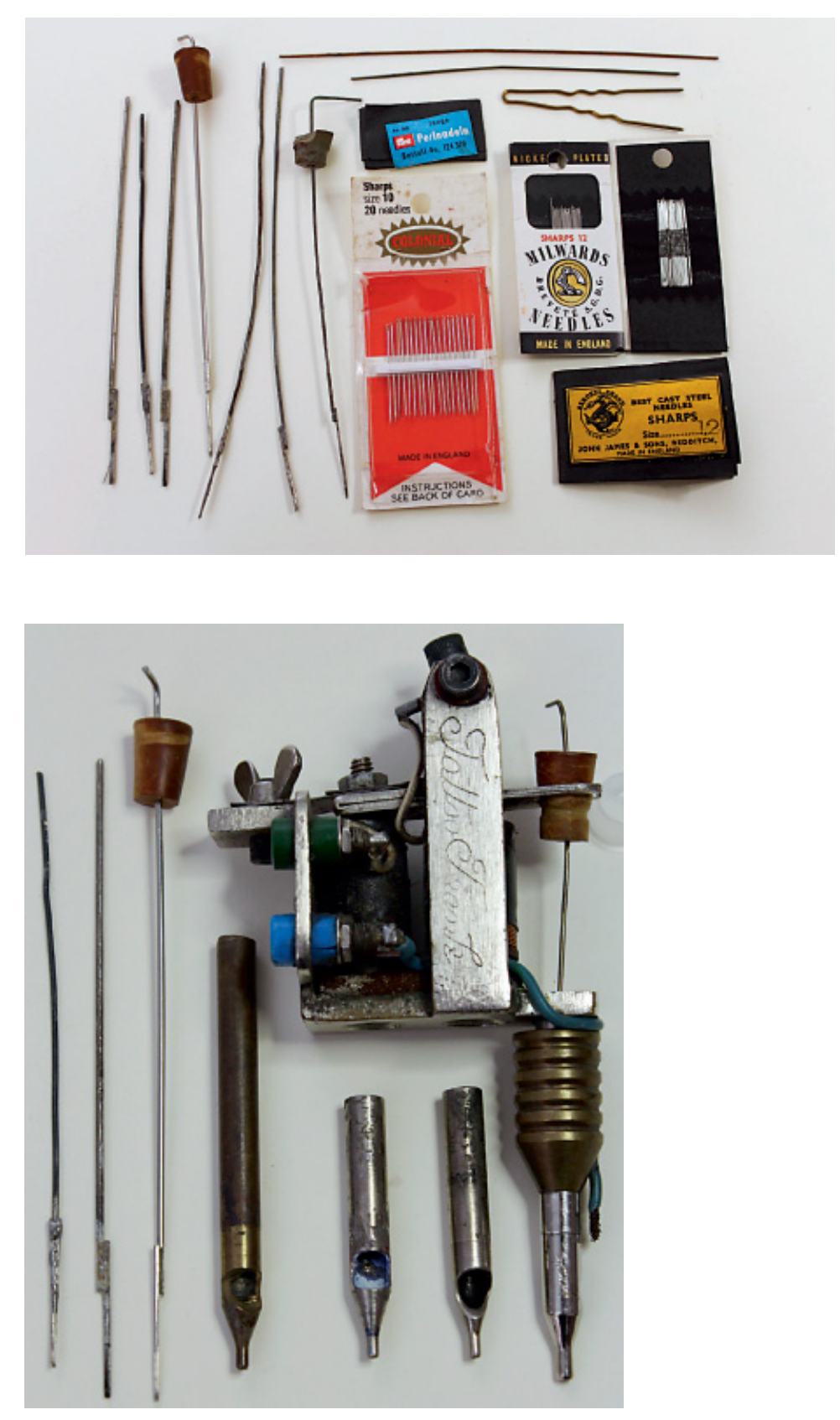

Fig. 12. This is a typical Danish finger-switch machine with a fixed grip and tube from the late 1970s that I have used myself. Some of these were still in use by the late 1980s, and their needles would often be left in for months - we didn't know any better! The used needles are lying next to the machine, and the tube still shows remnants of dried colour both inside and out. They were difficult to clean. options and/or a spring dimmer that will cushion the impact of the needle. What they share is their sound. A coil machine can be very noisy, while rotary machines only make a humming sound - an advantage for nervous customers.
Other advantages include their almost total lack of vibration and their low weight (some weigh below $50 \mathrm{~g}$ ). This is beneficial to those tattoo artists who have wrist problems because the very old coil machines not only made a lot of noise, 
Fig. 13. Needles from the 1970 s were mounted on spokes and hairpins.
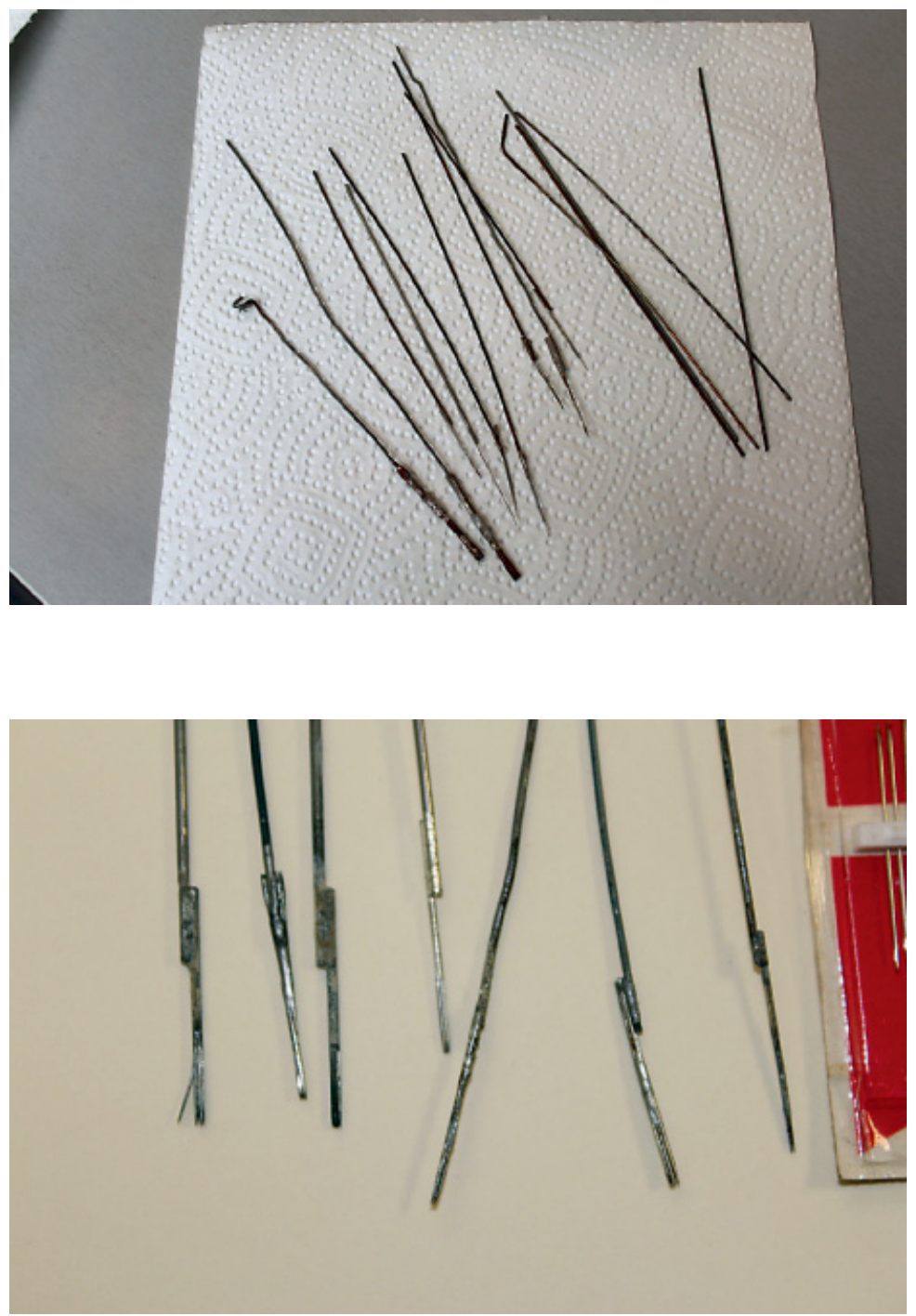

Fig. 14. These are the tip ends of used needles from the 1970s. They were often ordinary iron needles that could rust. Not such a good thing for a tattoo. not until the late 1980s that we tattoo artists - at our own initiative - started working with sterilised, replaceable tubes and needles.

The grips consist of the grip itself and an inner tube that is made of steel, brass or aluminium. Some Danish and European tattoo artists fitted a wooden handle to a fixed grip, but since the late 1980s, most professional tattoo artists have been using stainless steel grips and tubes, which are cleaned and sterilised along with the needles in an 
Fig. 15. These electrical razors have been rebuilt into tattoo machines and were often used in prisons. A prisoner with a bit of technical skill would easily be able to do this.
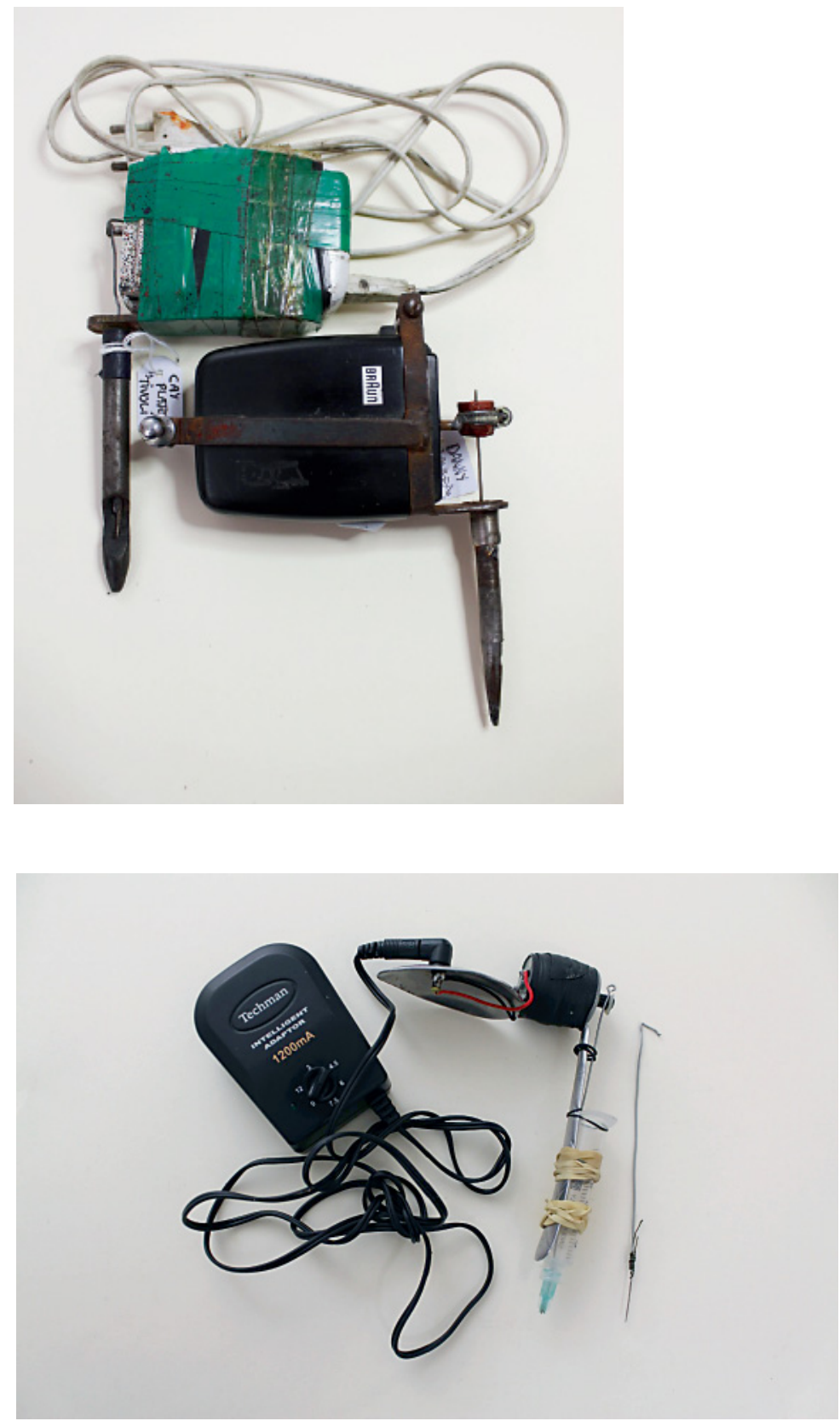

Fig. 16. This is a more recent prison machine. The engine is probably from a cassette player, and if you add to it a bit of scotch tape, a bent spoon, a ball-point pen and a sewing needle, you've got yourself a tattoo machine. autoclave. This is now on the way out, as a wide variety of affordable, disposable plastic tubes are being marketed.

For many years, we exclusively used needles that were soldered in a round formation. Three needles for lines and seven needles for colour were the most common, and when lacking anything better, ordinary sewing needles could be used. But buying quality needles became easier over the years; particularly, British factories began manu- 


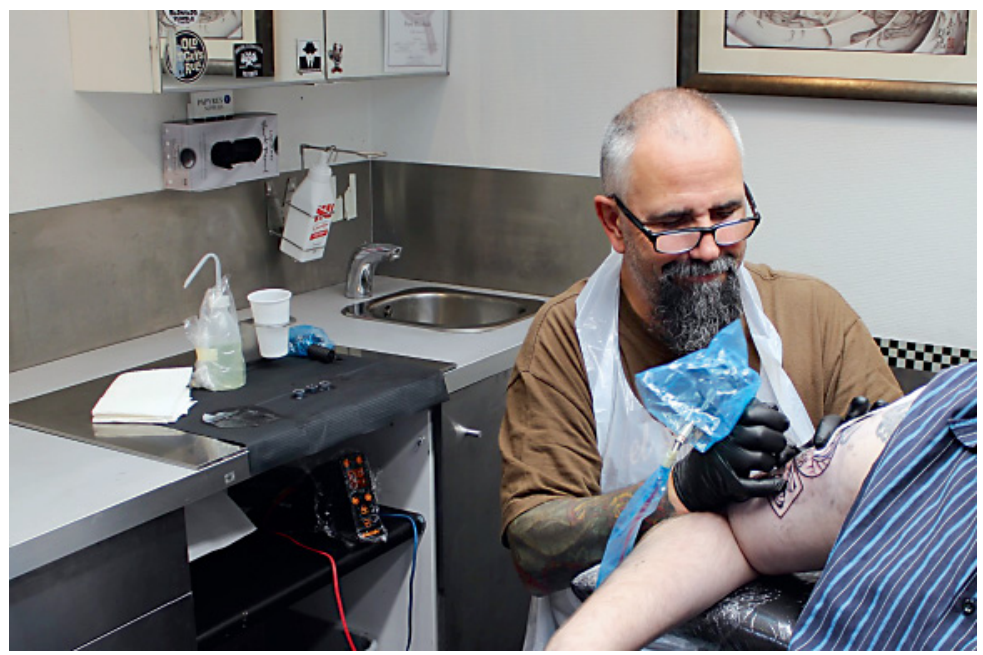

Fig. 17. Here, I am working with some of the machines and various disposable materials that have been described above. Working with modern machines and disposable materials is a big change from when I embarked upon my career in 1977 , and the rapid development within my line of work has not stopped yet. The good thing is that we no longer have to do everything ourselves, for example, solder the needles, mix the colours, and build the machines. But, a lot of the charm that surrounded the old-fashioned tattoo parlours has definitely disappeared. I guess that is the price you have to pay for becoming popular and going mainstream; it still has been fantastic to be a part of it all.

facturing high-quality needles. Today, all needles are stainless steel. In the USA, magnums, rows of needles positioned in a slightly spread-out position on top of each other, have begun to be used and after a while we adopted this technique as well. For large tattoos and for fine shading, these needles can be very efficient. There are numerous types of needles, either long tapers or short tapers that indicate the point of the needle; \#12/035 mm is most commonly used, and $\# 10 / 030 \mathrm{~mm}$ is a type that mainly is used for lines, but there are many different contraptions round liner, round shader, flat shader, magnum, curved magnum.

\section{Afterword}

The development and popularity of the tattooing business since the year 2000 have been incredible. When I started out as a tattoo artist in the late 1970s, we were trying to refine the old sailor motifs. Today's tattoos can be veritable works of art. The business that was once quite small is now an industry, and machines, colours and techniques have been developed beyond belief. It has been fantastic to follow the development of tattooing and still be a part of it today. I am thankful for having been allowed to contribute to this book. 